\title{
A sociedade de rostos \\ Mulheres sem rosto como indício de novo humanismo \\ nas redes sociais ${ }^{1}$
}

Isabelle Anchieta

As mulheres sem rosto no Paquistão: a violência contra a identidade humana

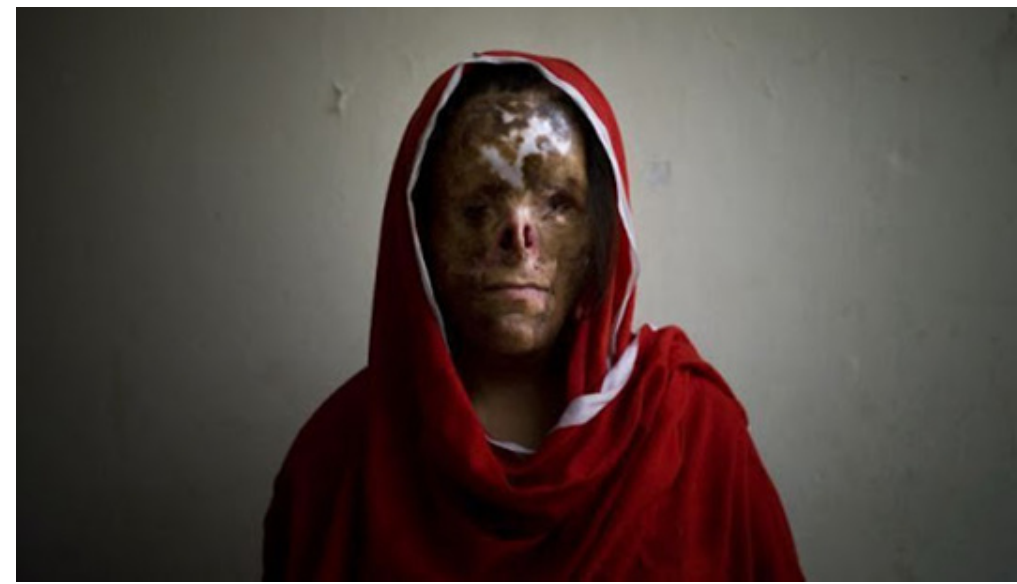

A paquistanesa Najaf Sultana fotografada pelo espanhol Emílio Morenatti, 2009

1. O presente artigo recebeu menção honrosa na vi Competição Mundial Jovens Sociólogos 2013/2014, organizada pela Associação Internacional de Sociologia (ISA), com apoio da Unesco. 
Difícil fixar o olhar no que sobrou da ideia de um rosto em Najaf Sultana. O véu vermelho, aberto, revela uma face duplamente encoberta. A pele queimada - com manchas marrons, brancas e vermelhas - abre espaço para dois orifícios no lugar do nariz. Ainda que não possamos reconhecer seus olhos, ela nos fita. Dois buracos negros nos indicam a correspondência. A posição da imagem - a frontalidade diante do virtual espectador - é um convite incômodo de reciprocidades. Porém, há uma pessoa diante de nós. E é o seu pedido de reconhecimento do nosso olhar à sua humanidade que mobilizou uma rede de pessoas. O direto de todos a uma face humana.

Por que essa reivindicação - que tem como pano de fundo a acentuação do processo individualizante - torna-se cada vez mais importante socialmente? É o que tento responder neste trabalho, observando a circulação das imagens de mulheres paquistanesas sem face nas redes sociais brasileiras, assim como o debate e a mobilização promovidos pela visibilidade mundial. Observarei, na reação nacional e mundial a elas, o indício de um processo social que as contém e as transcende: a crescente identificação humana para além das fronteiras nacionais e das diferenças culturais. No fortalecimento e na afeição por uma ideia até então muito vaga: a humanidade ${ }^{2}$.

Tento compreender qual é o papel das imagens nas disputas por reconhecimento ampliado. Dito de outra forma, de que maneira tais imagens, que circulam nas redes sociais, atuam nessa cada vez mais complexa tendência global de integração social: na identificação estendida, na demanda por direitos humanos ou mesmo na formação de instituições transnacionais.

Para testar a validade dessas indagações e dessa proposta selecionei como estudo de caso as imagens das mulheres paquistanesas atacadas no rosto com ácido por seus companheiros. Tal escolha deu-se por algumas razões. Primeiro porque essas imagens indicavam o avesso da discussão que apresento - a de mulheres sem face -, o que nos possibilita compreender a importância socialmente conferida à imagem do rosto humano, fato que pode ser medido pela repercussão pública dessas imagens.

A mobilização encontrou especial expressão através de vídeos e fotografias. Em 2012 o filme Saving face, dirigido pela jornalista paquistanesa Sharmeen Obaid-Chinoy e pelo cineasta norte-americano Daniel Junge, ganhou o Oscar de melhor documentário. Em 2009, o fotógrafo espanhol Emilio Morenatti realizou uma série de imagens com mulheres vítimas do ataque de ácido intitulada Violência de gênero no Paquistão, recebendo o prêmio FotoPres '09. Imagens sobre as quais dedicarei especial atenção, dado o seu intenso uso e apropriações nas redes sociais brasileiras.

2. Para o sociólogo Norbert Elias (1994, p. 139), estamos presenciando o nascimento de um novo ethos mundial, em que especialmente "a ampliação da identificação entre pessoa e pessoa já é claramente discernível. Há muitos sinais da emergência de um novo sentimento global de responsabilidade pelo destino dos indivíduos, independentemente de seu Estado ou tribo". 
Para isso, acompanhei durante três meses fóruns de debate nas redes sociais brasileiras sobre o tema, coletando argumentos e embates que emergiam dessas interações. Em 2013, criei uma rede social denominada Individumanização. Atualmente há cerca de 12 mil participantes com nacionalidades distintas - destacando a presença significativa de muçulmanas e muçulmanos. Assim, pude tanto observar como também promover discussões e reflexões pelas redes, funcionando como observadora-participante, ainda que minha atuação se restrinja em compartilhar conteúdos gerados por terceiros: ONU, Human Rights Watch, Anistia Internacional, entre outros.

A segunda razão que motivou a escolha de imagens de paquistanesas era o contraste cultural e os entraves que as diferenças religiosas, étnicas e nacionais poderiam apresentar em relação ao Brasil, o que o sociólogo Norbert Elias chamou de efeitos de trava ${ }^{3}$. Tais diferenças eram importantes para testar a validade de uma solidariedade e compreensão humana para além das fronteiras nacionais. Realizei para isso a observação de fóruns de debate no Brasil - o maior país católico do mundo (64\% da população). No entanto, trata-se de católicos de "tipo especial", como revela Pesquisa de 2013 do Datafolha ${ }^{4}$. Os brasileiros revelam-se liberais e ocidentalizados nos costumes (aceitam o divórcio como algo natural, o casamento entre pessoas do mesmo sexo, o uso de anticoncepcionais e preservativos e mesmo o aborto - temas ainda não aceitos pelo Vaticano). Tal comportamento liberal dos brasileiros poderia apontar supostamente para um conflito cultural, um alheamento na identificação e desinteresse na relação com um país muçulmano - o que de fato não se observou, como veremos.

Rosto, estigma e identidade humana

Não ter um rosto parece ser um dos mais dramáticos estigmas sociais. A sua visibilidade e o seu difícil encobrimento tornam a imagem pessoal um pesado fardo no intercâmbio social, inviabilizando as oportunidades de trabalho, de afeto e de

3. O efeito de trava é a "[r] esistência a uniões pós-nacionais ou unidades supranacionais. Especialmente dada pelos habitus nacionais: língua; vínculo emocional com o país” (Elias, 1994, p. 179).

4. Segundo a pesquisa Religião, do Datafolha (2013), os católicos são os mais liberais entre os religiosos no Brasil: o uso de preservativos encontra um alto índice de aprovação (93\%), e o mesmo vale para a pílula anticoncepcional (85\%). Sobre se uma mulher pode celebrar uma cerimônia religiosa, a aprovação dos católicos (64\%) é maior que a dos evangélicos pentecostais (56\%) e dos não pentecostais (58\%). Perguntados sobre as uniões homossexuais, $41 \%$ se declaram favoráveis. Em comparação, ainda é menor que a aceitação entre espíritas (64\%) e adeptos da umbanda (53\%). Ainda dos católicos, 41\% se mostraram favoráveis à legalização do aborto. Mais da metade dos católicos (52\%) ainda defende um clero celibatário, embora se diga desanimada com os constantes casos de abuso e pedofilia. Por outro lado, antes um tabu, o divórcio já é aceito como natural para $67 \%$ dos católicos. 
aceitação social. "As crianças estão com medo de mim. Uma mulher no Paquistão como eu não tem valor" (Marshall, 2013) é o desabafo de Aziz Mai, vítima do marido após tentativa de fuga diante da ameaça do companheiro em vender a família. $\mathrm{O}$ rosto deformado é a marca visível de uma infinidade (não tão aparente) de controles, limites e agressões impostas às mulheres muçulmanas. Antes de ser queimada Aziz refugiou-se na casa da família, e lá foi espancada pelos irmãos que não aceitavam sua separação. Teve de fugir uma segunda vez, momento em que foi atacada pelo marido em uma estação de ônibus - provavelmente informado de seu paradeiro pelos cunhados. O marido foi preso, mas Aziz condenada a uma imagem "socialmente deteriorada" (Goffman, 1988). Expulsa de sua comunidade, foi obrigada a mendigar para sustentar os cinco filhos (alguns também parcialmente atingidos durante o ataque). "Nossa vida foi arruinada, estamos condenados a uma vida pior que a morte”, declara Aziz (Idem).

A constatação dramática da ruína social de sua imagem não é um exagero. $\mathrm{O}$ rosto é o nosso direito mais extremo de existência social e humana. Tem papel "talvez o mais central" (Elias, 1994, p. 155) para a identidade do eu e para a sociabilidade. Vale lembrar que o rosto é um atributo exclusivamente humano. Nenhum outro animal desenvolveu uma diferenciação desse nível. Ele permite que nos identifiquemos mutuamente, mesmo durante o nosso processo de envelhecimento. É como se o nosso aparato biológico corroborasse para a nossa segunda natureza - a social -; é a dependência do olhar alheio para a nossa existência no singular, pois "somente por conviverem com outras é que as pessoas podem perceber-se como indivíduos diferentes dos demais" (Idem, p. 160).

Por isso, a intenção do agressor não é, em geral, assassinar a vítima, mas lhe conferir um "atributo profundamente depreciativo" (Goffman, 1988) e inviabilizar, assim, suas futuras relações sociais. Depois do ataque, a jovem de quinze anos Sidra Javed passou a evitar conhecer pessoas novas, quase nunca sai de sua casa, na cidade de Lahore (Paquistão), somente o faz para continuar os tratamentos de reconstituição. Cega de um olho, sem parte do couro cabeludo, Sidra também tem partes do corpo queimadas. O seu agressor foi preso. "Fiquei muito aliviada, mas quando eu penso em como estou vivendo, como desfigurada eu sou, eu acho que a punição deveria ser muito pior", afirmou em depoimento no site da Acid Survivors Trust International (Asti, 2013)

Vergonha e autodepreciação. Conflitos internos provocados pela percepção do desconforto causado por sua presença junto aos demais. Sentimentos que não podem ser elucidados, exclusivamente, por uma perspectiva psicológica. É preciso entender

5. Site: http://www.acidviolence.org. 
sobretudo os dramas dessa "interação angustiada" ${ }^{6}$, da instável relação instaurada diante do outro, do medo de ser rejeitada e agredida por sua aparência. Relações e contatos dos quais não se pode escapar - por mais que se tente -, sob pena do próprio isolamento reforçar a sensação de fracasso pessoal.

Eis o impasse: assumir ou não uma imagem que não lhe pertence - imposta por um ato de violência. Assumi-la torna-se gradualmente um ato político de mobilização solidária com a condição das mulheres muçulmanas. A sua imagem - única - potencializa uma dor coletiva. Saira Liaqat é uma dessas mulheres que aceitou ser exposta publicamente. Segura nas mãos uma foto antiga - o seu rosto antes do ataque. Duas imagens de si: uma que lhe pertencia e outra sobre a qual ela não tem mais controle. Atualiza, contra a sua vontade, o ato de violência, enquanto sua imagem, impressa no papel fotográfico, apaga-se e distancia-se no tempo. A mudança da sua condição de jovem atraente para a uma face deformada e alheia à sua identidade é abrupta, quebrando sua posição social e forçando-a a alinhar-se à sua nova situação 7 .

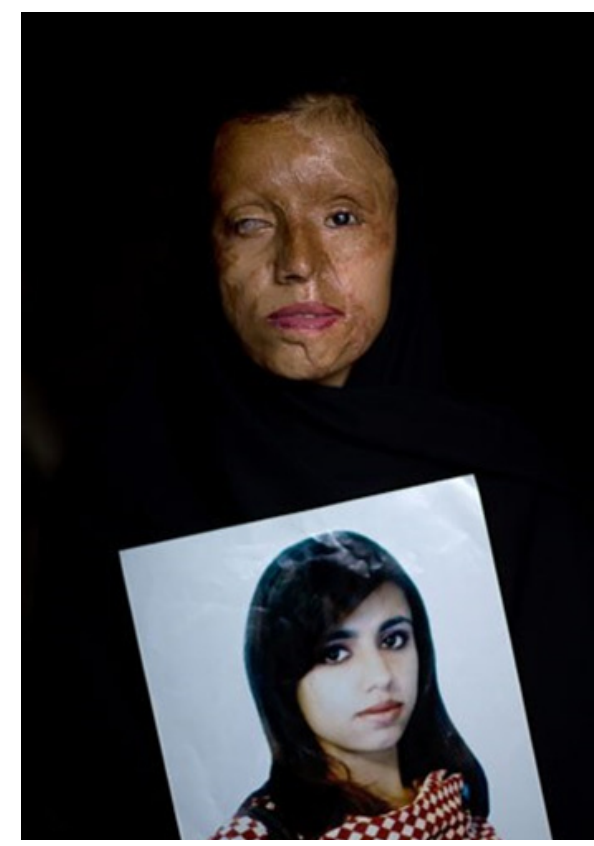

A paquistanesa Saira Liaqat é fotografada pelo espanhol Emílio Morenatti, 2009

6. “[O] medo que os outros possam desrespeitá-la por algo que ela exiba significa que ela sempre se sente insegura em seu contato com os outros. Isso representa um sistema quase fatal do sistema do eu. Em que a pessoa pensa: 'eu sou inferior, portanto as pessoas não gostarão de mim e eu não poderei me sentir segura com elas"” (Goffman, 1988, p. 15).

7. "O doloroso de uma estigmatização repentina pode ser o resultado não da confusão do indivíduo sobre a sua identidade, mas do fato de ele conhecer suficientemente a sua nova situação” (Goffman, 1988, p. 113). 
Ser mulher no Oriente: o abismo entre o islamismo e os costumes criminosos

Se a face deformada é um estigma "novo" com que elas têm de aprender a lidar rápida e dolorosamente, sua condição de mulher é um "estigma” com o qual convivem desde o nascimento. Um gênero sob risco constante de agressão - condição ainda mais dramática nos países orientais, especialmente aqueles que adotam as leis islâmicas. Segundo o Fórum Nacional Mundial de 2012, dezessete nações islâmicas estão entre as piores em políticas sociais.

Mas, paradoxalmente, violações dos direitos humanos não estão relacionadas com os preceitos do Alcorão e do Hadith - como em geral se imagina. Tais livros não estabelecem diferenças entre o homem e a mulher perante Deus. Muito pelo contrário, elas parecem obter proteções e virtudes especiais de Allah.

Em um trecho narrado na voz indireta de Allah, afirma-se: "Ó crentes, não vos é permitido herdardes as mulheres, contra a vontade delas, nem as atormentardes [...]. Harmonizai-vos com elas, pois se as menosprezardes, poderei estar depreciando seres que Allah dotou de muitas virtudes" (Alcorão, v. 19, p. 76). Consideradas assim pela Bíblia Oriental como seres criados por Allah e detentoras de "muitas virtudes", as mulheres sob esses preceitos teriam livre arbítrio para se casarem e mesmo divorciarem-se ${ }^{8}$.

A relação entre homens e mulheres recomendada pela narrativa não é, portanto, marcada pela sujeição, mas por uma troca de forças e habilidades que se supõem diversas. Em um trecho, essa horizontalidade é poeticamente ilustrada: "acercar-vos de vossas mulheres, porque elas são vossas vestimentas e vós sois dela” (Idem, v. 187, p. 54). Em um outro trecho sublinha-se essa relação eletiva e autônoma: "não vos esquecei da liberdade entre vós, porque Allah bem vê tudo quanto fazeis" (Idem, v. 237, p. 58). No entanto, parece que na prática e nos costumes muitos homens e mulheres muçulmanas se esqueceram disso, ou mesmo ignoram o conhecimento literário de sua religião, ficando a mercê de falsos mediadores. Paquistanesas, africanas, afegãs, iranianas, turcas, entre outras, crianças e mulheres muçulmanas são vítimas de uma série de abusos às suas liberdades individuais, como, por exemplo, indianas condenadas a estupros coletivos por tribunais populares locais (que funcionam à margem das leis do país). Em janeiro de 2014, mais um caso ganhou visibilidade internacional. Uma jovem de 20 anos moradora de Bengala, no leste do país, foi condenada a um estupro coletivo por ter cometido "o crime de se apaixonar" por um homem de uma aldeia rival. "O chefe da tribo ordenou que eu fosse desfrutada pelos homens

8. Há uma longa menção ao divórcio estabelecendo regras para que se consume, inclusive enfatizando a importância de o homem dividir o patrimônio e manter a mulher após a separação, adotando um tom protecionista. No versículo 34, diz-se: "Os homens são os protetores das mulheres" (Alcorão, p. 77). Para saber mais a esse respeito, ver versículos de 227 ao 241 (Idem, pp. 57-58). 
da cidade. Segundo suas ordens pelo menos dez ou doze, entre eles vários membros de uma mesma família me estupraram", relata a vítima (G1, 2014).

Não podemos deixar de mencionar também outra tradição social violenta que atenta contra a dignidade e a vida das mulheres orientais: a mutilação genital de crianças feitas em rituais coletivos especialmente no norte da África e Ásia. Calcula-se que cerca de 140 milhões de mulheres sofram com as consequências da mutilação, segundo dados da Anistia Internacional em 2014.

A amputação do clitóris das crianças ou até mesmo a costura dos lábios vaginais são práticas que garantiriam supostamente o controle da sexualidade feminina, impedindo o prazer nas relações sexuais e mantendo sua virgindade, uma espécie de capital simbólico usado como moeda de troca pelas famílias. "Não tem nada a ver com religião. Todas as meninas que são vítimas da mutilação também são vítimas do casamento forçado. A maioria é vendida quando criança a homens mais velhos. Eles não pagariam por uma noiva que não tivesse sido mutilada. É uma vergonha para as nossas comunidades e para os países que permitem essa prática. Os homens temem a sexualidade feminina, essa é a verdade”, denuncia a modelo e vítima da mutilação, Waris Dirie (G1, 2010).

Atualmente embaixadora da ONU, Dirie destaca também a confusão que se faz entre práticas culturais e a religião muçulmana e também o perigo de que agressões que se reproduzem e se repetem contra a mulher, em grande medida por omissão do Estado, se tornem "tradições" sociais - coerções e crimes travestidos de hábitos religiosos em grande medida gestados por um sistema de relações. Não há, por exemplo, nenhuma indicação no Alcorão às mutilações genitais, sugestão de estupro ou outro tipo de ataque físico. Apesar da interpretação radicalizada do Alcorão, vale enfatizar que o próprio livro prevê e recrimina esse excesso. Em uma passagem diz-se: "Ó adeptos do Livro, não exagereis em vossa religião e não digas de Allah senão a verdade" (Alcorão, v. 171, p. 86).

As imagens e as reportagens que circulam nos meios de comunicação e nas redes sociais tornam-se instrumentos centrais desse esclarecimento. Como é o caso mesmo de Waris Dirie, emprestando sua biografia ao filme com mesmo título, Flor do deserto, lançado em 2009. O sofrimento da menina e sua luta no combate às mutilações ganham dessa forma visibilidade, contribuindo para a conscientização de outras mulheres e mães que reproduzem tal prática, como revela o depoimento da muçulmana africana Fatomati: "Eu comecei a perceber que isso era só uma prática que não está escrita no Alcorão depois de começar a ver vídeos e reportagens na TV. Eu comecei a perceber que não tem nada a ver com a religião muçulmana"

9. Entrevista exibida pelo Porto Canal, em Portugal, em 3/4/2013. Disponível em https://www.youtube. com/watch?v=oWalcb3zfye, consultado em 3/3/2016. 
A informação circula em grande medida via imagens, mas que em regiões pobres da África depende ainda de mulheres voluntárias que percorrem as comunidades instruindo meninas, mães e avós. A ativista Efua Dorkenoo foi uma das ativistas pioneiras no que chama de ativismo de base. Há mais de trinta anos atuando na formação de mulheres que replicam a informação nas regiões pobres da África, ela se diz otimista com a gradual mudança de mentalidade. "As pessoas estão passando da ideia de que esta é uma prática religiosa e agora percebem que a mutilação é uma grave violação dos direitos humanos"10.

Em 2013, a Organização para a Cooperação Islâmica concluiu também que muitas nações islâmicas restringem o acesso à educação. Segundo dados do Unicef, mais da metade da população é analfabeta, e destas $70 \%$ são mulheres. O Paquistão ocupa também uma das piores classificações no ensino infantil: 5,1 milhões de crianças não frequentam a escola, e as dedicadas às mulheres são alvo de uma série de atentados terroristas. Só em 2008, mais de quatrocentas escolas foram destruídas, inclusive uma criada por um paquistanês chamado Ziauddin Yousafzai, pai da adolescente Malala - a mais jovem mulher a receber o prêmio Nobel da Paz, em 2014.

Ziauddin é um homem muçulmano que contraria o estereótipo do oriental, agindo de forma mais liberal do que a mãe de Malala em sua formação. "Minha mãe acreditava que estava escrito no Corão que as mulheres não deviam sair de casa nem conversar com homens que não fossem seus parentes. Meu pai lhe dizia: "Pekai, purdah, não é o véu. Purdah está no coração" (Yousafzai, 2013, p. 127). O pai será fundamental para conscientizar Malala da importância da educação e da separação entre religião e costumes. Em um depoimento, ela diz: "Das mulheres espera-se que cozinhem e sirvam seus pais e irmãos. Enquanto os homens e os meninos podem andar livremente pela cidade. [...] É a tradição. Decidi muito cedo que comigo as coisas não seriam assim. Meu pai sempre me disse: 'Malala será livre como um pássaro"” (Idem, p. 34).

A adolescente tornou visível uma série de restrições às liberdades individuais promovidas pelos talibãs através de um blog, sendo por isso vítima de um atentado a caminho de sua escola. A repercussão do caso na mídia ofereceu projeção internacional à luta, quase solitária, de Malala e de seu pai na defesa e garantia de sua educação e de outras meninas.

Ela tornou audível o drama das jovens muçulmanas. Em suas palavras: “O Islã nos deu esse direito ao dizer que todo menino e menina devem ir à escola. No Corão está escrito que devemos buscar o conhecimento, estudar com afinco e aprender sobre

10. Documentário Mutilação genital feminina, produzido por Equality Now Africa Rising, 2011. Disponível em https://www.youtube.com/watch?v=M4mQfqJa6J8, consultado em 01/06/2014. 
os mistérios do nosso mundo" (Idem, p. 164). Denunciando que "o Talibã liquidou nossos valores e, em última análise, os valores do Islä” (Idem, p. 163).

Como apontam as conclusões do relatório produzido em 1999 pela organização internacional Human Rights Watch, sagazmente intitulado "Crime ou costume? Violência contra mulheres no Paquistão" (Burney, 1999), a situação da mulher paquistanesa depende consideravelmente da localização geográfica e da classe social. Mulheres de classe média e elevada que vivem nas áreas urbanas possuem mais oportunidades de melhor educação, salários e trabalho. Porém, infelizmente representam uma minoria, já que $75 \%$ da população ainda vive no meio rural, são pobres e com poucos privilégios. Chamando a atenção para as "desvantagens estruturais da mulher", que são consideradas cidadãs de segunda classe, o relatório destaca a importância de atacar a "discriminação legal e social baseada em normas e atitudes culturais" (Idem), o que implica dizer na prática que são, entre outras coisas, impedidas de escolher seu parceiro afetivo, prosseguir nos estudos e ter uma carreira profissional. Obstruções que motivaram o ataque a jovem Saira. Obrigada a casar com um homem de sua família, ela queria terminar sua formação antes de assumir o relacionamento. Em 2003, quando tinha apenas vinte anos foi atacada pelo pretendente que não concordava com a continuidade dos seus estudos. Perdeu um dos olhos e foi submetida desde então a nove cirurgias plásticas.

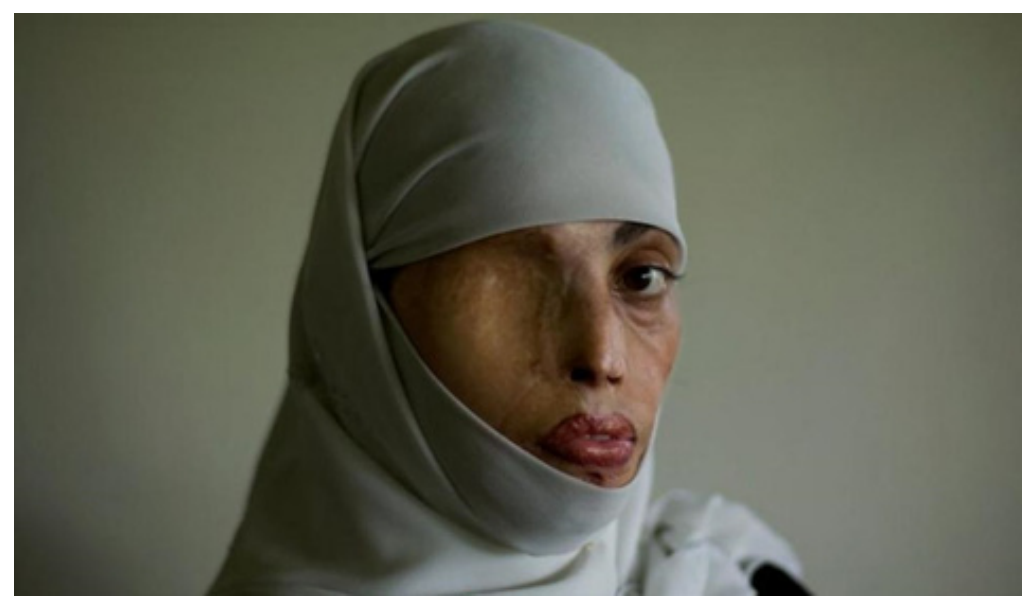

Saira, paquistanesa fotografada pelo espanhol Emílio Morenatti, 2009.

É no descompasso entre o desejo individual e as exigências coletivas que surgem as mulheres sem face, violentadas por seus parceiros e por sua família porque reivindicam possibilidades eletivas. Em todas as faces uma história parecida: Irum 
Saeed, Naila Farhat, Kanwal Kayum, Zainab Bubi, Munira Asef recusaram-se a casar e foram atacadas pelos homens que rejeitaram.
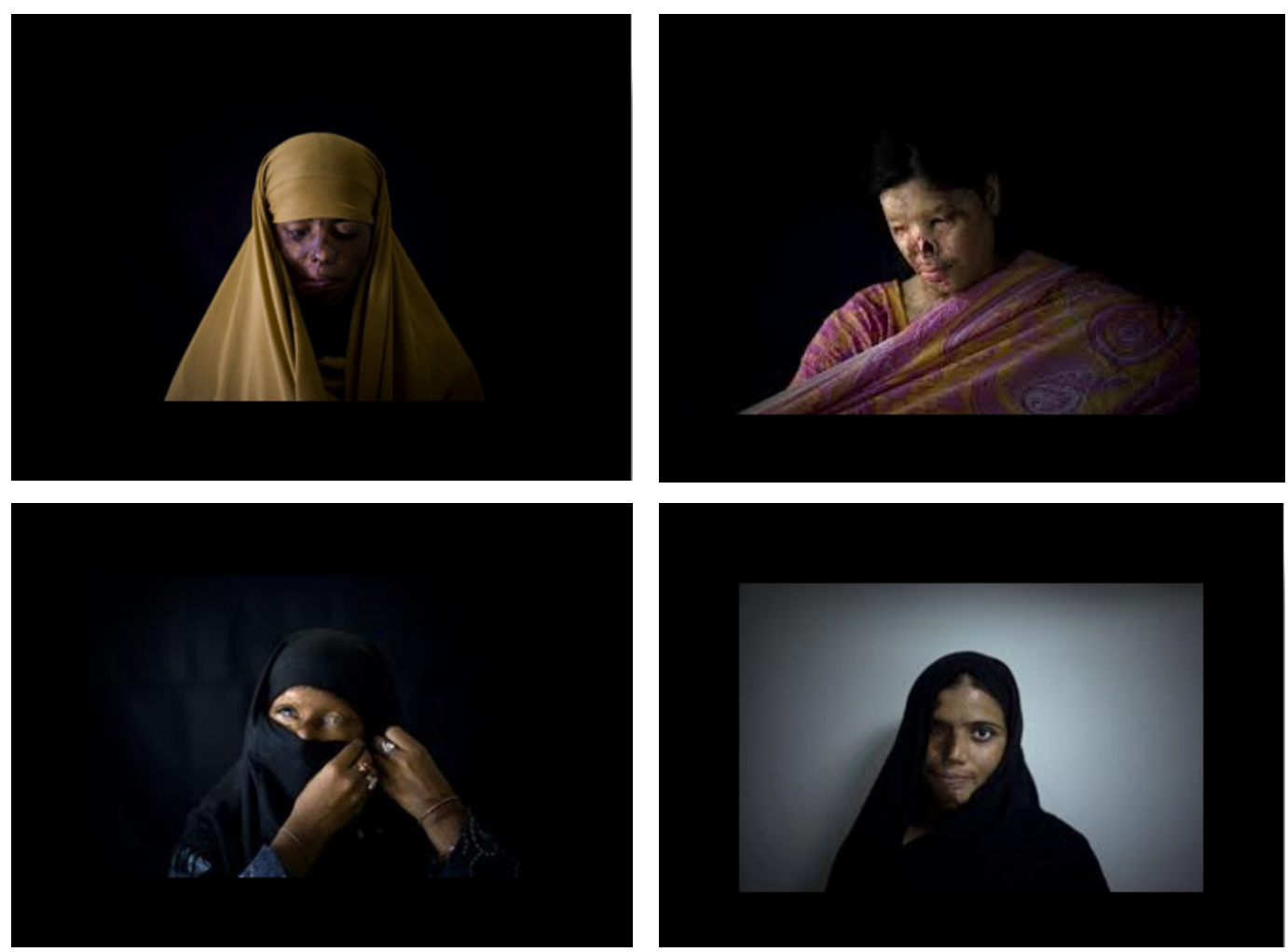

Paquistanesas fotografadas pelo espanhol Emílio Morenatti, 2009.

Mulheres condicionadas por uma rígida estrutura social que - se comparada às sociedades ocidentais - muda muito lentamente em se tratando das liberdades individuais. Conservam, de geração em geração, normas de conduta supostamente ancoradas em pressupostos religiosos, fato que acentua o contraste com o processo de secularização e individualização do Ocidente. Mudança motivada, em grande medida, pelas mulheres ocidentais.

Foram elas as principais responsáveis pela desarticulação da primeira e fundante ordem social: a família nuclear tradicional e seus fundamentos (casamento, maternidade e sexualidade). Os papéis sociais - pai, filho, homem, mulher - são profundamente abalados pelas "possibilidades eletivas emergentes" das mulheres ocidentais. Pois, apesar de o processo individualizante não ser uma invenção dos últimos séculos nem ter sido gerado exclusivamente pela mobilização das mulheres, 
ele, no entanto, ganha propulsão com a mudança do estatuto e da imagem da mulher nas sociedades capitalistas ou mesmo com a necessidade de sua inserção no mercado de trabalho como força produtiva. Elas passam, assim, a ter o direito de eleger o "projeto biográfico" como valor supremo, o que não significa imediatamente que tenha se emancipado ${ }^{11}$ ou se autonomizado - na medida em que a "individualização revela-se como a forma mais avançada de socialização dependente do mercado, do direito e da educação" (Beck, 2010, p. 194). Fato que não se dá sem resistência de movimentos contra a modernização, ou mesmo no descompasso de estruturas institucionais historicamente constituídas (leis, escolas, costumes etc.).

No entanto, ainda que consideremos essa defasagem e o risco de regressões do processo individualizante das mulheres ocidentais, podemos apontar uma diferença significativa e sentida com base na condição das mulheres orientais. Arrisco-me a afirmar que a reivindicação das mulheres paquistanesas pelo direito de eleger seu companheiro e sua carreira profissional possa estar motivada pela circulação e intercâmbio entre as formas de vida promovidas pela internet; mulheres que, na observação de mulheres de culturas diferentes da sua, passam a desejar uma liberdade de ação e escolha mais ampla.

Nesse sentido, a imagem das mulheres sem face é, sobretudo, sintoma do agravamento das tensões culturais que apontam a ascensão do desejo das paquistanesas por uma vida própria. Tensões que não se circunscrevem mais aos limites da cultura e da nação. Aliam-se a elas, agora, olhares distantes.

\section{Direitos humanos: a formação da rede de proteção supranacional}

Em média são registrados cem casos de mulheres que sofrem esse tipo de agressão facial por seus parceiros a cada ano no Paquistão - fato que se agrava desde o ano de 1999. Uma violência que se tornou prática social, disseminando-se culturalmente como uma forma de coação e controle contra a individualização das paquistanesas. Prática que só pode se reproduzir diante da tolerância do Estado - apenas 10\% dos agressores foram presos. A maioria dos casos não chega à justiça, impedidos de prosseguir por uma proteção tácita aos agressores. "Em 80\% dos casos, quando as sobreviventes dos ataques de ácido vão a polícia, eles ignoram, não registram o caso para preservar o responsável", afirma o investigador Mohammad Khan (Naeem, 2012).

Na ausência da proteção dos agentes do Estado no controle a essa violência, presenciamos a formação de uma nova rede de proteção transnacional com a criação de

11. "Muitos associam individualização com individuação (formação da personalidade, emancipação). Isto pode ser correto. Mas talvez também o seu contrário seja” (Beck, 2010, p. 191). 
diversas organizações destinadas a proteger essas mulheres. A mais atuante delas no combate ao ataque de ácido é a Acid Survivors Trust International (Asti). Sediada na Inglaterra, a Asti foi criada em 1999 por John Morrison com a missão de combater "a violência com uso de ácido em todo mundo", concentrando-se nos países onde esses casos se tornaram uma prática social: Paquistão, Bangladesh, Colômbia, Afeganistão e Índia.

A Acid Survivors Foundation (ASF), criada em Bangladesh, oferece também apoio médico, psicossocial e jurídico às vítimas de ataques com ácido "para garantir sua reconstrução física e reintegração na sociedade", de acordo com o seu site ${ }^{12}$. Conta para isso com diversos apoios internacionais. A fundação recebeu 10 milhões de euros do governo australiano, em 2012, destinados a "promover mensagens de direitos humanos e a conscientização das normas internacionais, incluindo-as nos currículos de ensino fundamental e médio”, afirmou Raza Rumi, diretor do instituto na ocasião do recebimento da verba. Defendeu ainda que "temos de começar o processo de criação de um sistema de educação mais humana” (Naeem, 2012).

Outras importantes organizações que apoiam as ONGs vinculadas aos ataques de ácido são a Human Rights Watch e a Anistia Internacional, rede que conta atualmente com 3 milhões de pessoas em mais de 150 países, legitimada pela defesa dos direitos humanos ${ }^{13}$. Essas mobilizações globais já surtem efeitos práticos, atuando como forma de pressão aos governos locais. Em 2011, o Paquistão aprovou uma lei de pena mínima de catorze anos de prisão e multa equivalente a $\mathrm{R} \$ 20$ mil contra os agressores de ataques com ácido, seguindo o exemplo de Bangladesh, primeiro país a adotar lei específica na criminalização dessa violência. Desde 2009, o número de casos teve redução de quase 75\%, registrando oitenta casos em 2012, contra 496 ataques em 2002.

Tais redes supraestatais são também sintomas de um processo social mais estendido. Visto em retrospectiva, ${ }^{14}$ aponta para a criação de redes de proteção cada vez mais ampliadas, passando da dependência imediata da família, tribos/clãs para

12. Site: http://www.acidsurvivors.org.

13. No site da Anistia, seus organizadores definem o que entendem por direitos humanos: "são direitos e liberdades que todos têm, não importa quem sejam, nem onde vivam. Para viver com dignidade, os seres humanos têm o direito de viver com liberdade, segurança e um padrão de vida decente. Os direitos humanos não precisam ser conquistados - eles já pertencem a cada um de nós, simplesmente por sermos seres humanos. Não podem ser retirados de nós - ninguém tem o direito de privar qualquer pessoa de seus direitos". Disponível em http://www.amnesty.org ou ainda em Anistia Internacional Brasil: http://anistia.org.br.

14. "A função de uma unidade efetiva de sobrevivência vem agora, visivelmente deslocando-se mais e mais do nível dos Estados nacionais para as uniões pós-nacionais de Estados e, além delas, para a Humanidade" (Elias, 1994, p. 178). 
organizações mais amplas e complexas (os Estados-nação e os Estados unificados), que detinham até então o "monopólio da violência” (Weber, 2006) para, enfim, caminharmos para uma organização transnacional, em que a ideia de direitos humanos e de humanidade estão em ascensão.

A própria circulação dos termos é indício da existência social mais sentida dessa tendência humanizatória. Abandonando seu viés retórico ${ }^{15}$, a humanidade torna-se um meio eficaz de integração social como unidade de pacificação, proteção da integridade física e garantia de margem maior de escolhas individuais, conferindo um poder ao indivíduo para além da sua nacionalidade e condicionamentos culturais - que encontra nas redes sociais a sua forma de expressão e expansão.

\section{A imagem da humanidade nas redes e a cultura local como "efeito de trava"}

Curiosamente, a maturidade da ideia de direitos humanos não se restringe a redes institucionalizadas. Espalha-se nos fóruns de debates no interior das redes sociais em todo mundo, especialmente entre os brasileiros. Discussões ativadas pelas imagens. Entre elas, as do documentário Saving face (dirigido pela jornalista paquistanesa Sharmeen Obaid-Chinoy e pelo cineasta norte-americano Daniel Junge) de 2012 e as do fotógrafo espanhol Emilio Morenatti na série que intitulou Violência de gênero no Paquistão, realizada em 2009.

O olhar dos brasileiros sobre essas imagens produziu uma tensão particular: entre a cultura e os direitos humanos. De um lado, a resistência em debater a condição das mulheres paquistanesas, com o argumento de que "essa é a cultura deles". Ideia que funciona como um "efeito de trava" ao processo de identificação ampliada. Alguns participantes apontaram também o risco de uma intervenção internacional com pretextos supostamente humanísticos, encobertos por intenções econômicas e políticas.

Surpreendentemente, por outro lado, a maioria dos brasileiros que participou dos fóruns sobre o tema tendeu a adotar uma hierarquia entre a ideia dos direitos humanos e da cultura. Mecanismo que permitiu romper a barreira de esferas tidas até então como invioláveis de cada país. A cultura e a religião tornam-se, assim, gradativamente subordinadas à ideia de direitos humanos, autorizando todos a opinar e intervir dada a sua identificação com a condição humana dessas mulheres.

Podemos observar isso no depoimento de uma brasileira, em comentário postado no site de uma revista ${ }^{16}$, em março de 2012, que trazia a reportagem sobre o docu-

15. "O conceito de humanidade ainda tem implicações de um idealismo sentimentalista. Isto tem prejudicado sua evolução para a categoria de um simples instrumento factual” (Elias, 1994, p. 188).

16. Site: http://colunas.revistamarieclaire.globo.com/mulheresdomundo/2012/03/02/saving-face. 
mentário Saving face. Com o apelido de "Dani", ela afirma: "Isso é um crime contra os direitos humanos, os países tinham que intervir neste país e castigar severamente os homens que fazem isso... isto não tem nada a ver com os costumes de um país. Isto é maldade mesmo".

Outro fórum, chamado Outer Space, do portal Terra, foi iniciado a partir das imagens do fotógrafo espanhol Emilio Morenatti. O debate também girou em torno dessa tensão, com privilégio para a ideia de supremacia dos direitos humanos sobre a cultura nacional. Intitulado "Brutalidade e covardia: mulheres paquistanesas desfiguradas", o debate teve início em novembro de 2009, atraindo uma centena de brasileiros.

O primeiro a se manifestar, com o codinome "Makenshi", defende que "manifestações culturais (religiosas, ritualísticas, costumeiras etc.) que atentem contra os direitos humanos (vida, dignidade e honra) deveriam ser severamente punidas pelas autoridades, não importa o lugar. Se as autoridades não o fizerem, que o façam as forças estrangeiras". Em seguida uma pessoa de codinome "mig29gsxr" se solidariza com as mulheres paquistanesas dizendo: "só espero que em algum lugar haja conforto para essas mulheres que tanto sofreram". "Éris" responde lembrando que "no Brasil há muitos casos de violência contra a mulher", mas em seguida outro participante lhe diz, com certa impaciência, que as diferenças estão na impunidade.

Um dos participantes contraria a posição dos comentários postados até então. Justifica o ataque como uma atitude cultural: "claro que é desumano, algo que não aceitamos, mas é a cultura deles, cultura é cultura", diz o participante "Furlan", que em seguida recebe grande quantidade de reaçóes. A primeira delas, de uma pessoa com codinome "fbr", diz: "não concordo com essa de cultura é cultura, isso é fanatismo e crime contra a humanidade. Já que fazem tanta guerra por causa de petróleo, poderiam intervir a força contra esse tipo de brutalidade. Um país assim não merece ser soberano". Uma pessoa de codinome "Dr. Haller" utiliza a legitimidade da Anistia Internacional para defender seu ponto de vista, compartilhando link para relatório da situação das mulheres no oriente. "É. Só eu que acho, Eu e a anistia internacional http://www.amnesty.org/en/library/info/ASA 11/005/1997”. Outro faz menção aos organismos internacionais: "Decerto, organizações internacionais e ONGs deveriam cair em cima e protestar ativamente". Outra pessoa, de codinome "Rvu Ga”, menciona o impacto das imagens e diz: "Fortíssimas fotos [...] é tremenda infelicidade, traz revolta, estamos no século XXI, e ainda nos deparamos com essas coisas”.

Em comum os depoimentos levantam importantes questões:

- A consciência da ideia de direitos humanos supranacionais e o conhecimento de organismos mundiais que os representam. 
- A supremacia dos direitos humanos em relação à religião e à cultura, ainda que seja um tema que gere discordâncias e que a distinção entre religião e costumes criminosos não seja totalmente clara.

- A legitimidade de intervenções de organismos transnacionais, desde que dirigidos à proteção dos direitos humanos.

- A solidariedade e a comoção - através de imagens - com pessoas de outro país e cultura.

Esse último ponto me parece central: perceber que o debate se instaura a partir e sobre as imagens humanas que circulam amplamente pelas redes sociais e sua significativa capacidade de produzir uma identificação humana para além das diferenças nacionais entre o Brasil e o Paquistão. Retratos que atuam nos processos sociais de forma relativamente autônoma e que "não podem ser considerados como abstrações, nem como substitutos de elementos positivos, mas como termos de uma problemática que concretiza atitudes geradoras de uma organização concentrada da experiência" (Francastel, 1982, p. 91).

Imagens humanas que promovem e testemunham uma nova forma de integração social, em que a identidade cultural-local se torna subordinada à identidade humana-global. Nessa nova ordem de importâncias é recorrente a proposta intervencionista/ humanista nas falas dos debatedores, no sentido de que algo deve ser feito para proteger essas mulheres independentemente dos valores culturais e religiosos a que estão submetidas, o que não se manifesta como um sentimento ingênuo. Muitos participantes revelam-se temerosos com o uso da ideia de direitos humanos como forma de dominação política e econômica entre os países. Consciência que conduz os debatedores a deslegitimar os Estados-nação como capazes de proteger os indivíduos. Legitimidade e confiança são, por sua vez, atributos delegados a organizações internacionais como mediadoras ideais de conflitos e injustiças tidas, agora, como humanas.

Esse "humanismo institucionalizado socialmente" - às margens dos Estados-nação - nasce na encruzilhada entre a compreensão da partilha universal dos mesmos direitos e a comoção afetiva com histórias particulares, em que rostos e sociedade, individual e coletivo, particular e global, sabem-se potencialmente relacionados na rede social. Um processo que poderia ser denominado de individumanização.

\section{Conclusão}

As imagens nas redes sociais podem agenciar mudanças na relação de poder entre os indivíduos e os Estados-nação. Momento em que as pessoas passam a pro- 
blematizar a soberania de seus governos, mas também a refletir sobre a cultura local e as desigualdades estereotípicas (étnicas, raciais e sexuais) em defesa de algo que os transcende e os liga: a humanidade.

Ideia até então muito vaga que começa a ganhar materialidade e força por conta de uma demanda crescente por cidadania, participação política e direitos humanos, o que indica uma nova tendência global nas relações humanas; uma nova forma de identificação e integração que, curiosamente, tem como força motriz a aceleração da individualização.

Nessa direção, as imagens atuam na construção de sujeitos cientes dos deveres e direitos supranacionais no século XXI. Para testar essa hipótese, apresentamos essa pesquisa de curta duração. Observei como a visibilidade mundial e a comoção causada pela circulação de imagens de mulheres desfiguradas com ácido no Paquistão passaram a ser fator decisivo na pressão aos legisladores para criar leis mais rigorosas contra os agressores. Desde então o número de casos teve redução de quase $75 \%$.

Assim, a presente pesquisa não só contribui para o campo de estudos teóricos de deliberação democrática contemporânea como também oferece instrumentos e estratégias de mobilização e de ações políticas inovadoras. Desvelando dinâmicas que instauram novas formas de deliberação democrática, coloca em jogo um número maior de atores sociais e argumentos nas tomadas de decisão.

Assim, a presente pesquisa não só contribui para o campo de estudos teóricos em direitos humanos como também oferece instrumentos e estratégias de mobilização e de ações políticas inovadoras. Desvelando dinâmicas que instauram novas formas de deliberação democrática, coloca em jogo um número maior de atores sociais e de argumentos nas tomadas de decisão.

Para ampliar a validade desse achado pretendo continuar investigando ações similares para entender o alcance, os limites e os mecanismos dessa nova dinâmica de poder, em que aparentemente os indivíduos ou grupos podem acionar mundialmente um debate democrático em prol da defesa dos direitos e das liberdades individuais.

Trata-se de um momento em que os "costumes criminosos" passam a ser questionados tanto no Ocidente como no Oriente e no qual se promove um gradual descolamento da imagem hierarquizada do valor humano em prol da concepção de unidade e igualdade. Concepção que se globaliza aos poucos, disseminando-se culturalmente nos países por meio da interferência cada vez mais forte dos órgãos internacionais, do intercâmbio visual e do conteúdo via internet.

Isso acelera e incentiva a disputa de indivíduos e grupos por autoconfiança, autorrespeito e autoestima. Sentimentos que só podem ser gerados nas relações intersubjetivas mediadas pelas lutas de afeto, de direitos e de estima social, como bem sistematizou o sociólogo Axel Honneth (2003) na obra Luta por reconbecimento. 
No entanto, seria redutor acreditar que a disputa por visibilidade e reconhecimento tenha surgido com a chegada da internet e das redes sociais no século XXI. Homens e mulheres sempre encontraram meios de comunicar suas ações e pensamentos, ainda que nosso tempo nos reserve algo impactante: a ampliação e a massificação dessa disputa individualizante. Há uma profusão de imagens, rostos, vidas e pretensões que se ampliam na mesma grandeza do alcance das formas comunicativas. Todos tentam ser vistos, ouvidos e lidos nesse novo ambiente de integração social - que demanda reciprocidades em um ciclo infindável de considerações mútuas. Trata-se de um processo que tende simultaneamente ao individualismo e às interações ampliadas ou "compartilhadas".

Momento em que a face assume a imagem mais expressiva do direito de individualização em esferas de reconhecimento cada vez mais alargadas, desvelando a configuração social originária que liga um a todos. Pois, o rosto é a imagem que nos singulariza e permite perceber que existe um eu e um nós em relação, sendo o elemento visual fundante da sociabilidade. Por isso, elegi realizar este artigo por seu incômodo avesso: as mulheres sem face e sua reivindicação de um olhar humanizante, na medida em que elas nos revelam a importância do direto de todos a uma face humana.

Seriam, então, as faces "gradativamente individualizadas" a nova imagem da socialização e integração humana pós-nacional no século Xxi? Um novo humanismo que explicita a conexão um-todos? Algo que poderia nomear de "individumanização"?

Essa pesquisa de curta duração antecipa tal hipótese teórica levantada no percurso de oito anos de trabalho ${ }^{17}$ : elucidar de que forma a crescente importância da imagem humana "gradativamente individualizada" participa e testemunha novas formas de organização e integração social. Processo que aponta para uma mudança nas relações de poder, em que os indivíduos passam a questionar os estereótipos sociais, a soberania dos Estados-nação e até mesmo a cultura local,

Processo individualizante que não produziu, como se previa, o isolamento social (o Homo clausus), mas tem ativado uma nova forma de socialização, vínculos, solidariedades e trocas. Um novo estágio de consciência em que "estamos aprendendo a ver nossa imagem, simultaneamente no espelho da autoconsciência e em outro espelho, maior e mais distante" (Elias, 1994, p. 85).

17. Refiro-me à minha pesquisa de doutorado, em que remonto a imagem da mulher no Ocidente moderno desde o século Xv até o século Xx. Como não abordo a contemporaneidade, realizei a presente pesquisa de curta duração para antecipar e validar hipóteses já observadas na pesquisa histórica de longa duração. Intitulada Imagens da mulher no Ocidente moderno, a tese foi defendida em 16 de setembro de 2014, no Departamento de Sociologia da Universidade de São Paulo, com orientação de Maria Arminda do Nascimento Arruda. A tese recebeu distinção acadêmica pela banca composta por Fernando Novais, Lilia Schwarcz, Massimo Canevacci e Ferdinando Martins. 
"A sociedade de rostos" é, portanto, uma tentativa de elucidação no campo das imagens dessa relação indissociável entre o indivíduo e a sociedade. Uma imagem que nos possibilita entender essa engenhosa dinâmica social que gradativamente amplia e massifica os processos sociais de individualização, na medida em que aumentam as oportunidades de comunicarmos nossas particularidades. Uma espiral de reconhecimentos recíprocos e disputas por atenção e visibilidade que podem nos conduzir a um nível de integração social sem precedentes históricos: o individumanismo.

\section{Referências Bibliográficas}

Alcorão. (2010). Trad. Samir El Hayek. São Paulo, Folha de São Paulo.

AsTI - Acid Survivors Trust International. (2013), "Tough law sees acid attack conviction rate triple in Pakistan”. Asti, 4 abr. Disponível em http://www.acidviolence.org/index.php/news/ tough-law-sees-acid-attack-conviction-rate-triple-in-pakistan, consultado em 4/3/2013.

BECK, Ulrich. (2010), Sociedade de risco: rumo a uma outra modernidade. São Paulo, Editora 34.

Burney, Samya. (1999), Crime or custom? Violence against women in Pakistan. Nova York, Human Rights Watch. Disponível em http://www.hrw.org/reports/1999/10/19/crime-or-custom, consultado em 3/3/2016.

Datafolha. (2013), "Religião”. Disponível em http://datafolha.folha.uol.com.br/ opiniaopublica/2013/07/1314857-fatia-de-catolicos-e-a-menor-em-duas-decadas.shtml, consultado em 22/07/2013.

Elias, Norbert. (1994), A sociedade de individuos. Rio de Janeiro, Zahar.

Francastel, Pierre. (1982), A realidade figurativa. São Paulo, Perspectiva.

G1 - Portal de Notícias da Globo. (2010), “'É impossível descrever a dor', diz modelo sobre circuncisão feminina". G1, 5 jul. Disponível em http://g1.globo.com/mundo/ noticia/2010/07/e-impossivel-descrever-dor-diz-modelo-sobre-circuncisao-feminina.html, consultado em 5/7/2010.

(2014), "Conselho tribal indiano ordena estupro grupal de jovem como castigo". G1, 23 jan. Disponível em http://g1.globo.com/mundo/noticia/2014/01/conselho-tribal-indiano-ordena-estupro-grupal-de-jovem-como-castigo.html, acesso em 23/1/2014.

Goffman, Erving. (1988), Estigma. Rio de Janeiro, LtC.

Honneth, Axel. (2003), Luta por reconhecimento. São Paulo, Editora 34.

Marshall, Penny. (2013), "Acid attacks: crimes of hate rather than honour". itV , 8 fev. Disponível em http://www.itv.com/news/2013-02-08/acid-attacks-crimes-of-hate-rather-than-honour, consultado em 8/2/2013.

Naeem, Waqas. (2012), "Australia helps acid victims in Pakistan get back on their feet". The Express Tribune, 14 dez. Disponível em http://tribune.com.pk/story/479623/australia-helps-acid-victims-in-pakistan-get-back-on-their-feet, consultado em 11/4/2016. 
Weber, Max. (2006), “A política como vocação”. In: . Ciência e politica: duas vocaçôes. São Paulo, Martin Claret.

YousAfZaI, Malala. (2013), Eu sou Malala. São Paulo, Companhia das Letras.

\section{Resumo}

A sociedade de rostos: mulheres sem rosto como indício de novo humanismo nas redes sociais Neste artigo busco entender de que forma a crescente importância da imagem humana "gradativamente individualizada" instaura e testemunha novas formas de organização e integração social no século XXI. Mostro como as imagens nas redes sociais podem agenciar mudanças na relação de poder entre os indivíduos, os Estados-nação, a cultura local e as desigualdades estereotípicas (étnicas, raciais e sexuais) em defesa de algo que os transcende e os liga. Momento em que o rosto emerge como imagem da humanidade. Parto para essa reflexão de seu avesso: a ausência de uma face - drama de mulheres paquistanesas que tiveram seus rostos desfigurados por ácido por seus companheiros, uma prática cultural que se agrava desde 1999. Problematizo a circulação, o debate e a solidariedade que essa incômoda imagem despertou nas redes sociais brasileiras. Discuto de que forma a violência contra a expressão mais visível da identidade social promove uma comoção para além das fronteiras nacionais e simbólicas, instaurando a ideia de humanidade.

Palavras-chave: Sociologia da imagem; Mulheres muçulmanas; Redes sociais; Humanismo.

\section{Abstract}

The society of faces: faceless women as an indication of a new form of social integration

This paper tries to discover how the growing importance of the human image "gradually individualized" incorporates and witnesses the new forms of organization and social integration in the 21 st century. Time in which the face is consolidated as image of humanity. Its opposite is assumed for this reflection: the absence of a face. The drama of the Pakistani women who suffered the disfigurement of their face through acid thrown by their peers - a cultural practice that is compounded from the year 1999. I am interested in discussing about the impact, the debate and the solidarity that the unpleasant image has been awakened in the Brazilian social networking. I want to understand how the violence against the most visible expression of the social identity promotes a commotion beyond ethnic, racial and cultural borders, introducing the idea of humanity. Keywords: Sociology of the image, Muslim women; Social networks; Humanity.

Texto recebido em 31/10/2015 e aprovado em 31/10/2015. DoI: 10.11606/0103-2070. ts.2016.106947.

ISABELLE ANCHIETA é doutora em sociologia pela Universidade de São Paulo e mestre em comunicação social pela Universidade Federal de Minas Gerais. E-mail: isabelleanchieta@gmail. com/isabelleanchieta@usp.br. 


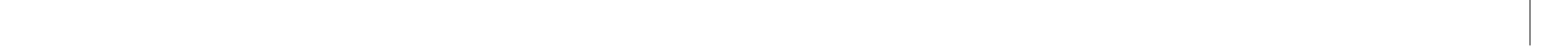

